\title{
Railroad ballast behavior in triaxial compression tests with and without geogrid
}

\author{
Andrei Petriaev ${ }^{1, *}$, and Victor Ganchits ${ }^{1}$ \\ ${ }^{1}$ Emperor Alexander I St. Petersburg State Transport University (PGUPS), Moskovsky pr. 9, St. \\ Petersburg, 190031, Russia
}

\begin{abstract}
This paper highlights recent laboratory studies at Emperor Alexander I St. Petersburg State Transport University, using large-scale cylindrical triaxial apparatus, which helped quantify the geogrid performance in railway ballast. The triaxial shear strength tests were conducted on ballast with and without geogrid. Effect of geogrid layers quantity on the ballast stress-strain behaviour were studied. The experimental results indicate that the geogrids have improved ballast bearing capacity up to $25 \%$.
\end{abstract}

\section{Introduction}

Ballast and soil of the railway roadbed-working zone are in a complex stress state under three-axis compression caused by the influence of rolling stock, natural factors and forces from its own weight. Therefore, it is necessary to study the main relationships between the stresses and strains of stabilized soil under three-axis compression to create the methods for calculating the deformation and strength appeared in the roadbed. The parameters of these dependencies will be included in the calculation formulas as quantitative characteristics of the stabilized soils mechanical properties.

The analysis of the conducted studies of ballast materials mechanical properties shows the increasingly important role of the materials strength and deformation characteristics accurate determination under three-axis compression [1-3]. These parameters are used in a number of modern applied software packages for sleeper bearing behaviour calculations and modelling as input data $[4,5,10]$. Some parameters that are obtained with the modelling of the required operating conditions will allow predicting the long - term track behavior, to develop reasonable requirements for the characteristics of the initial materials and to determine the measures to improve the track reliability as a whole.

The results of laboratory tests give reliable values of the calculated characteristics, when the test method is maximally linked to the conditions in which the ballast is in the railway track construction. Laboratory tests should take into account to the maximum extent the ballast properties and operating conditions of the railway track.

It is possible to recreate the natural initial stress state in the soil sample in the stabilometric tests, by setting the lateral pressure equal to the horizontal stresses in the ballast thickness at vertical stresses, which are equivalent to overlying layers dead load.

\footnotetext{
* Corresponding author: pgups60@mail.ru
} 
Cylindrical soil samples usually test in stabilometer under axisymmetric deformation conditions with the possibility of lateral expansion.

Large-scale modelling of ballast behavior was carried out at different confining pressure. The use of three-axis compression device is one of the most common methods of laboratory studies of soils strength and deformation characteristics [6-8]. It is almost impossible to conduct shear tests on the ballast sample in a typical three-axis compression device, due to the large grain size. Ballast grains can have a maximum size up to $63.0 \mathrm{~mm}$ according to Russian standards GOST 7392-2014, while the diameters of conventional samples for stabilometrical tests are 40-60 $\mathrm{mm}$. Therefore, the maximum diameter of the ballast particles is reduced or a large three-axis compression device is used.

Many researchers point out that the strength and deformation characteristics of crushed stone depends on the particle size. The obtained results of strength and deformation characteristics in a conventional three-axis compression device [9] may be inaccurate due to the forced reduction in the size of ballast particles.

Increasing the sample size leads to device design complication and makes test process more difficult. In addition, the size of the sample is limited by the amount of ballast samples taken during geological works. Studies have shown that for testing on vacuum and hydraulic stabilometers the sample diameter for sand should be at least $4 \mathrm{~cm}$, and for the crushed stone at least $20 \mathrm{~cm}$. with the ratio of sample height to diameter at least 2 .

To overcome this problem, a large-scale ballast tests were carried out using a large cylindrical three-axis compression device with a natural particle size sample.

\section{Device for three-axis crushed stone tests STX-600}

The STX-600 system allows carrying out research of ballast physical and mechanical properties at a high technical level with the maximum imitation of real operating conditions.

The large-scale three-axis compression apparatus (Fig.1) takes into account the heterogeneity of ballast with a maximum size of fractions up to $63 \mathrm{~mm}$ by using a sample with a diameter of $300 \mathrm{~mm}$ and a height of $700 \mathrm{~mm}$.

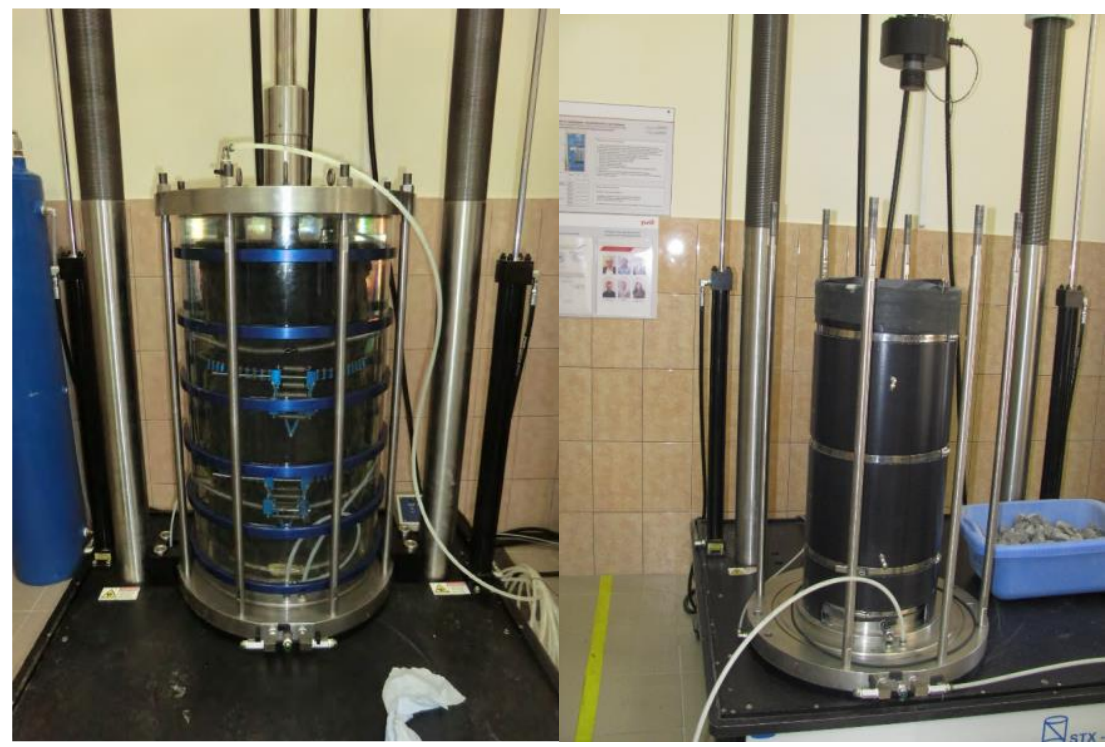

Fig. 1. Device for three-axis ballast tests STX-600. 
The main elements of the device are:

- cylindrical chamber,

- axial loading device,

- chamber pressure control unit,

- chamber pressure measurement system,

- devices for measuring axial and volumetric deformations.

The pressure control system in the stabilometer chamber prevents it from changing during the test.

\section{Ballast property and geogrid}

Ballast is a sharp angular coarse particles of volcanic granites crushing. The grain size distribution is shown in figure 2. The selected particle size distribution used in lab tests is typical for Railways JSC "RZD" according to GOST 7392-2014.

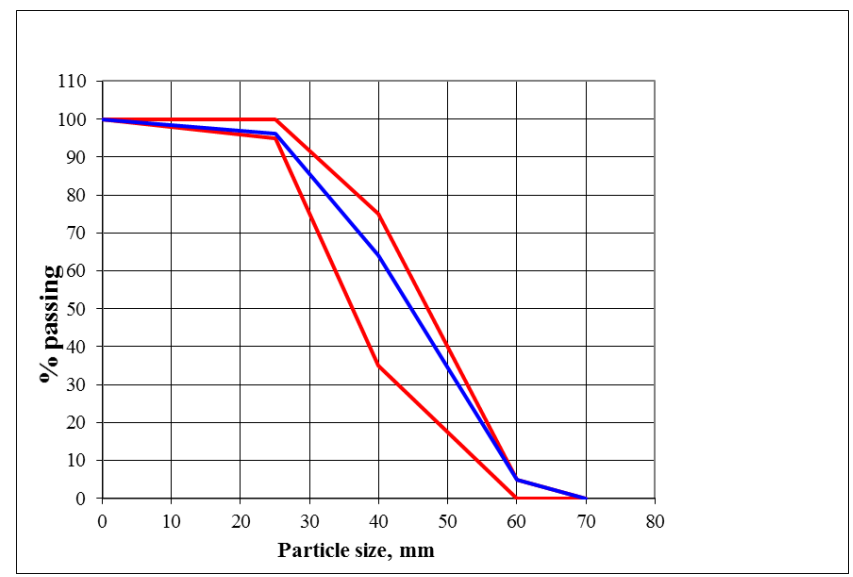

Fig. 2. The plot of ballast particles size distribution.

The geogrid, which was used to stabilize the ballast in the laboratory model, was polypropylene biaxially oriented type SS30. Tensar Ltd. is supplying it on Russian Railways to stabilize the sub-base.

\section{Preparation of ballast samples for testing and test procedure}

The ballast was carefully sifted using standard sieves, and different grain size proportions were mixed according to the selected grain size curve.

A lower plate is installed on the base of the stabilometer with the help of a portal crane. The membrane is put on the lower plate and fixed on it with clamps.

A detachable mold is assembled by means of tie clamps and pins and then it is installed on the bottom plate. The membrane is stretched on the top of the mold evenly and is incurved over to it. A tube with a vacuum is connected to the channel of the lower plate for a tight fit of membrane to the walls of the mold.

Then the mixed ballast was placed inside the rubber membrane and then compacted into four layers, each approximately $170 \mathrm{~mm}$ thick, using a hand-ramming. The samples mass specific weight were $15.4-15.6 \mathrm{kN} / \mathrm{m} 3$, which represent the typical ballast density in the field.

The upper plate was installed on the sample by means of crane and 2-ring bolts, the membrane was putted on it and fixed with a clamp. After connecting the necessary hoses, 
the sample was vacuumed and maintained for 5 minutes. The sample retains its shape under vacuum, the mold is disassembled and removed from the bottom plate.

The device for measuring ring (diametral) deformation DEF-SRCP-300 and LVDN sensors are mounted on the sample. The stabilometer chamber and its top plate with a loading rod are installed by means of portal crane and slings. The stabilometer is set to the working position on the table of the power frame by means of an air cushion under the bottom plate.

After filling the chamber by water, a confining pressure is created in the stabilometer, the vacuum in the sample, which was created to hold its shape, is discharged and preload of the sample is set through the vertical loading rod. The load rod is connected to the force sensor by tightening the coupling nut. The pressure sensors, LVDT and load control systems were connected to PC and their readings were processed using the WIN-CATSADV software. After this operation, the STX-600 system is ready for testing.

The crushed rock samples were compacted by a confining pressure of 20 to $80 \mathrm{kPa}$ to investigate the effect of the confining pressure on the ballast strength and deformation characteristics.

Shear tests were carried out at a loading rate of $1 \mathrm{~mm}$ per minute, which allowed to completely dissipating the pressure concentration on the soil particles. The loading was continued to a vertical deformation of about $16 \%$.

After the test, the ballast samples were sieved to separate the fine fraction and weighed.

\section{Stress-strain behaviour of ballast with and without geogrid}

The dependence of strain on the stress deviator for fresh and reinforced ballast under monotonic three-axis load is shown in Fig. 3.

The vertical pressure increasing leads to increasing of the sample deformation and this dependence is not linear. This dependence is characterized by a significant area of plastic deformation of crushed stone from $1 \%$ deformation to failure at $15 \%$ vertical deformation. All ballast samples come in the limit state regardless of the lateral pressure. The sliding surface was not found in these shear tests up to $16 \%$ axial strain.

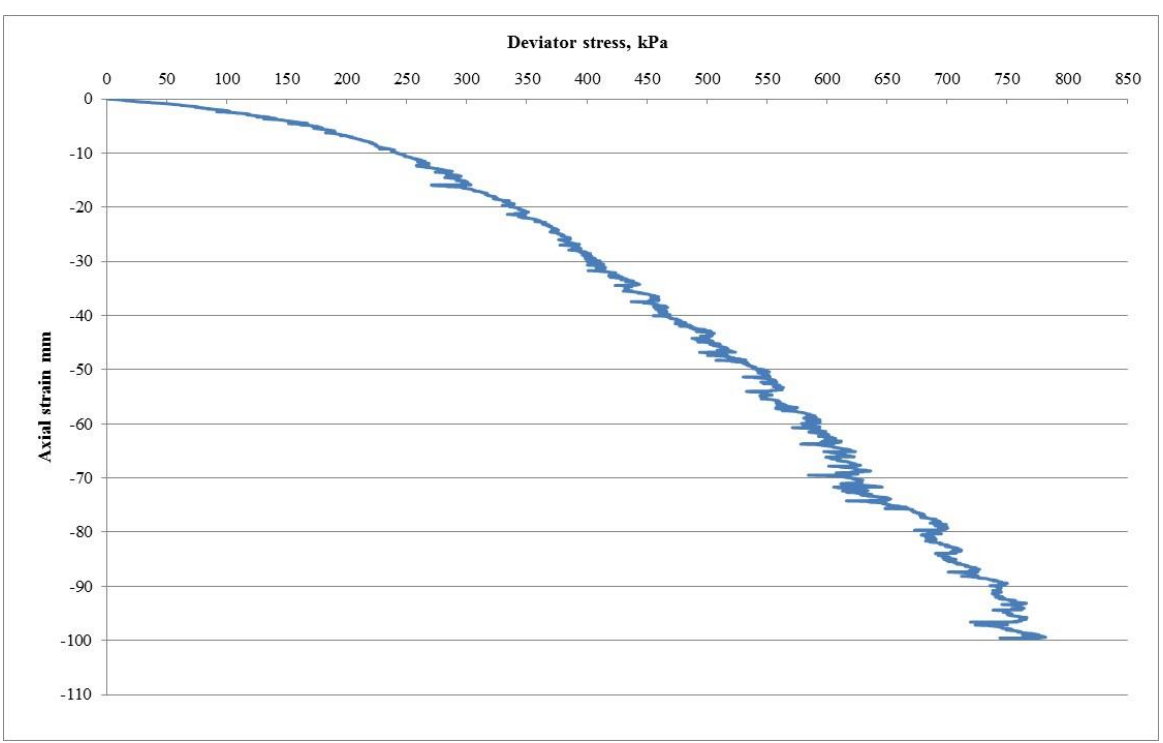

Fig. 3. Stress-strain ballast behavior under triaxial shearing with $60 \mathrm{kPa}$ confining pressure. 
In the process of loading, the ballast particles have an irreversible displacement and rotation relative to each other that leads to residual deformations. If the ballast is loose, the deformation process is accompanied by the compaction and re-packing of the particles and by the significant reduction of volume (contraction). This behavior is shown as minor spikes at the initial stage of loading. The intensive grains destruction is begun with the increasing of pressure, as a result, a pore volume is reduced and the compaction process is continued. This stage is shown as significant spikes in the graph. The soil compaction usually leads to it hardening. The grains crushing leads to the increasing in the number of contacts, therefore, to the distribution and reduction of the load acting on them. In this case, the shear resistance is increased until it reaches the resistance of compacted ballast.

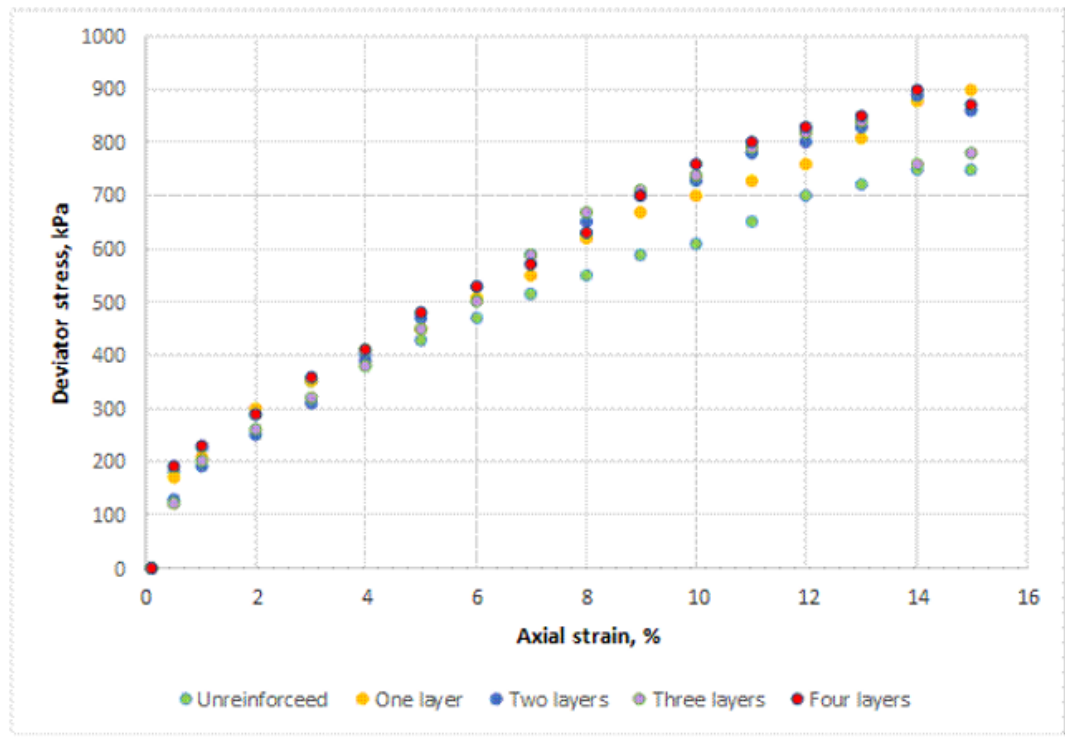

Fig. 4. Ballast strength tests with and without geogrid.

Figure 4 shows that the stress-strain state of the reinforced ballast at three-axis shear is similar to fresh ballast, except that the shear strength of the stabilized ballast is greater at the same lateral pressure. Three zones on the diagram can be distinguished - the zone of conditional elastic work, the zone of compaction (plastic deformation) and the zone of destruction.

It should be noted that the stabilized ballast samples perceive a larger load already at a vertical deformation of the order of $2 \%$ and this difference increases with the deformation growth, reaching $20-25 \%$ at the moment prior to destruction.

One layer of geogrid increases the sample perceived load by $10-15 \%$, two layers by 18 $22 \%$, three layers by $25 \%$. The fourth geogrid layer do not significantly affects on the perceived load. These results confirm the previously conclusions about the "influence zone" of the geogrid in the ballast in $12 \mathrm{~cm}$. from each side [10].

As a practical implementation of laboratory studies, it is possible to reduce the ballast layer thickness from $40 \mathrm{~cm}$ to $30 \mathrm{~cm}$ by means of laying geogrid in the middle of this layer (Fig.5). In this case, two main problems have been solved: the stress reducing on the subgrade top and the reducing of ballast deformability [11]. 


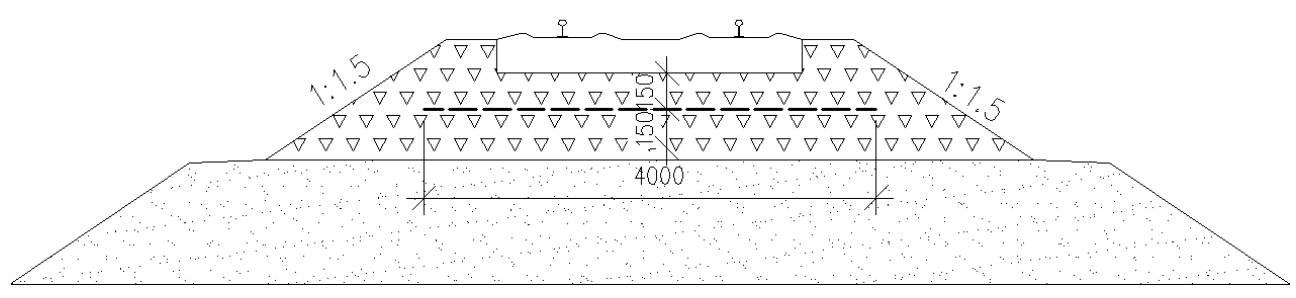

Fig. 5. Ballast stabilization.

\section{Conclusion}

The results of the triaxial tests clearly show that the ratio of principal stresses during the destruction of reinforced ballast is much higher than the fresh ballast, which determines their large values of peak angles of internal friction. Therefore, for geogrid stabilized ballast, angle of internal friction at a confining pressure of $60 \mathrm{kPa}$ is 61 degrees, while for fresh crushed stone it is of the order of 57 degrees, which is close to the previously obtained value of 55 degrees [12]. The railway structure stability may be increased by geogrid laying in ballast.

\section{References}

1. B. Indraratna, D. Ionescu, H.D. Christie, J. of Geotech. and Geoenvir. 124, 439-449 (1998)

2. G.M. Latha, V.S. Murthy, Geotext and Geomem 25, 23-32 (2007)

3. C. Atalar, B.M. Das, E.C. Shin, D.H., Kim, Proc. 15th Int. Conf. on Soil Mech. Geotech. Engg. 3, 2045-2048 (2001)

4. A.V. Petryaev, I.N. Zhuravlev, Application of geomaterials for construction and reconstruction of transport facilities, Proceedings of the III International scientifictechnical conference (SPb, 2013)

5. Y. Qian, D. Mishra, E. Tutumluer, H.A. Kazmee, Geotext and Geomem. 43, 393-402 (2015)

6. D.Zhao, E.G.Nezami, Y.M.A. Hashash, J. Ghaboussi. Eng. Comput. 23, 749-770 (2006)

7. G.P. Raymond, R.J. Bathurst, Canadian Geotech. Journal 31, 547-554 (1994)

8. J. Eisenmann, G. Leykauf, L. Mattner, Proc. 5th International Heavy Haul Railway Conference, Beijing, 193-227 (1993)

9. B. Indraratna, W. Salim, D. Ionescu, D. Christie, Proc. 15th Int. Conf. on Soil Mech. And Geotech. Engg, Istanbul 3, 2093-2096 (2001)

10. A.V. Petryaev, I.N. Zhuravlev, Proceedings of the 43 scientific and technical conference, St. Petersburg, 119-122 (2001)

11. A. Petriaev, Proc.of the Int. Scien. Conf. Transportation Geotechnics and Geoecology (TGG-2017) 189, 660-665 (2017) DOI:10.1016/j.proeng.2017.05.105

12. B. Indraratna, W. Salim, C. Rujikiatkamjorn, Advanced Rail Geotechnology Ballasted Track (CRC Press, 2011) 